\title{
Preparing technicians for photonics industries and organizations
}

John Souders, Dan Hull

John Souders, Dan Hull, "Preparing technicians for photonics industries and organizations," Proc. SPIE 8481, Optics Education and Outreach II, 848104 (15 October 2012); doi: 10.1117/12.928882

SPIE Event: SPIE Optical Engineering + Applications, 2012, San Diego, California, United States 


\title{
Preparing technicians for photonics industries and organizations John Souders, Dan Hull \\ National Center for Optics and Photonics Education \\ 324B Kelly Drive, Waco, Texas 76710
}

\begin{abstract}
U.S. photonics organizations need about 800 new photonics technicians each year. Thirty-one community and technical colleges have approximately 700 students enrolled in photonics related programs; about 275 of them complete their coursework and enter the workforce each year. A disparity exists between the demand and supply of qualified photonics technicians in the U.S. OP-TEC, the National Center for Optics and Photonics Education is a consortium of seven colleges, under the leadership of the University of Central Florida, and sponsored by NSF. OP-TEC's mission is to increase the quantity and quality of photonics technicians prepared at two-year colleges. OP-TEC maintains the National Photonics Skill Standards for Technicians, provides curriculum models, teaching materials, faculty training/professional development and planning services to strengthen existing college photonics programs and to attract and support new ones. OP-TEC is converting its text materials to E-Books to support students in technical programs. Through OP-TEC's recruitment efforts 84 additional colleges are interested in initiating new photonics programs. The OP-TEC Photonics College Network (OPCN) consists of 28 colleges that are currently providing photonics education. This fall OPCN will lead an additional national effort to further educate employed photonics technicians through on-line courses, complemented by lab experiences at nearby colleges. OP-TEC is expanding its outreach to photonics employers and colleges by regionalizing its approach to offering its services. OP-TEC is also planning to develop new curricula and instructional materials for AAS programs to prepare Precision Optics Technicians. This paper will detail OP-TEC's work with particular emphases on its materials and services.
\end{abstract}

Keywords: photonics, lasers, technicians, education, AAS, skill standards, STEM, precision optics, OP-TEC, National Science Foundation/ATE

\section{INTRODUCTION}

The National Center for Optics and Photonics Education, OP-TEC, is a National Science Foundation (NSF) Center of Excellence. Under the guidelines of NSF's Advanced Technological Education (ATE) program, OP-TEC has two main responsibilities. One is to focus on the comprehensive reform of technological education in a field that is central to maintaining the security and economic competitiveness of the United States. The other is to catalyze a broad national network of academic institutions and industrial entities that are interested in this particular technology. To meet these guidelines, OP-TEC has defined its mission as "Increasing the supply of well-educated photonics technicians by building and strengthening the capacity and quality of photonics education in U.S. two-year colleges." As this mission implies, OP-TEC's main thrust is to build a network of two-year colleges with educational programs that will provide the U.S's photonics industry a workforce capable of maintaining national security and global competitiveness.

Since its inception in 2006, OP-TEC has examined the supply and demand issues related to photonics technicians. In 2008, OP-TEC conducted a study to determine the capacity of U.S. colleges to produce photonics technicians. ${ }^{1}$ The results of the study indicated that 600-700 students are enrolled in programs that can lead to technician-level employment in the photonics industry. However, only 250-300 students were completing these programs each year and entering the photonics workforce. Data collected in 2012 from OP-TEC's Photonics College Network indicate, that since 2008, the number of students entering the workforce from two-year colleges has only slightly increased to between 275 300 .

To determine the demand side for photonics technicians, OP-TEC commissioned in $2009^{2}$, and again 2012, the University of North Texas, Survey Research Center (UNTSRC) to survey over 4000 U.S. photonics companies to determine how many photonics technicians these companies employ and the number they will need in one year and five years. The results of the 2012 study showed that over 19,100 photonics technicians are currently employed in the U.S.,

Optics Education and Outreach II, edited by G. Groot Gregory, Proc. of SPIE Vol. 8481

$848104 \cdot$ C 2012 SPIE $\cdot$ CCC code: 0277-786/12/\$18 - doi: $10.1117 / 12.928882$ 
over 1590 additional photonics technicians will be needed next year, and approximately 4115 photonics technicians will be needed in the next five years. A full report on the 2012 study will be available in fall 2012 at www.op-tec.org. When the results of the supply and demand studies are compared, it is clear that for the U.S. to meet its demand for photonics technicians, community and technical colleges must substantially increase the numbers of their graduates or program completers. OP-TEC's mission statement provides a clear indication of its commitment to meet this challenge.

The OP-TEC team includes industry representatives and skilled educators from flagship colleges that have proven track records in supporting U.S photonics employers. OP-TEC collaborates with a consortium of colleges whose efforts are coordinated and directed by its PI, Dan Hull, an engineer with over 13 years of experience in laser R\&D and management. OP-TEC's three Co-PI's are Dr. Fred Seeber (Camden County College), Dr. Chrys Panayiotou (Indian River State College) and Dr. M.J. Soileau (University of Central Florida/Center for Research and Education in Optics and Lasers). The six Partner Colleges are Camden County College (NJ), Indian River State College (FL), Indiana University of Pennsylvania (IUP) (PA), Indian Hills Community College(IA), Tri-County Technical College (SC), Irvine Valley College (CA), and Central Carolina Community College (NC). The OP-TEC staff includes Dr. John Souders, Director of Curriculum and Christine Dossey, Associate Director of Partnerships and Communications.

The remainder of this paper will present a brief review of OP-TEC's first six years, outline how OP-TEC supports and benefits employers, and provides insights into OP-TEC's future work.

\section{OP-TEC'S FIRST SIX YEARS}

OP-TEC's mission has remained constant throughout its six years of operation, but its goals have changed to reflect the changing environment of the photonics industry and constraints on two-year colleges that serve this industry. Initial goals were designed to 1) guide OP-TEC effort's in developing resources for assisting colleges in implementing photonics programs, 2) strengthen the photonics programs at its Partner Colleges, and 3) recruit additional two-year colleges to implement photonics offerings. These initial goals provided direction for OP-TEC to effectively pursue its mission and 4) establish its leadership among photonics educators and employers as a national resource for increasing the quality and size of the nation's photonics technician workforce. However, as OP-TEC assessed the college environment and other issues in meeting its mission, it became clear that its initial set of goals needed to be adjusted to more effectively address "Capacity Building". A major impediment to growing "capacity" is the very low enrollment in most of the photonics colleges, which leads to low numbers of student completers, and in some cases, closing the photonics programs.

To emphasize capacity building in its future operations, OP-TEC decided to pursue its mission with revised goals. These new goals place more emphasis on regionalizing OP-TEC's services through the leadership of its Partner Colleges, providing more educational opportunities for employed photonics technicians, strengthening its college network (OPCN), adjusting model curriculum structures to build photonics courses on existing core curricula and developing higher quality and more flexible instructional products and services. The following are OP-TEC's new goals:

1. Serve as the national leader for optics and photonics technician education.

2. Provide up-to-date, employer-validated resources to improve teaching and learning in optics, lasers and photonics technician education.

3. Expand the number of educational courses and programs in optics and photonics offered by colleges and high schools.

4. Provide education and training for administrators, counselors, high school teachers, and community college faculty members to prepare them to (a) design new photonics technology programs (b) infuse photonics into programs in photonics-enabled technologies; and (c) teach optics, photonics, and laser courses.

5. Identify and support the emergence of new technologies, including alternative energy, that require technician knowledge and skills in optics and photonics.

These goals have led to significant accomplishments in OP-TEC's mission. 


\subsection{Development of the Photonics Skill Standards for Technicians}

A major accomplishment of OP-TEC was the development and publication of the National Photonics Skill Standards for Technicians, Third Edition ${ }^{3}$. Skill standards are employer specifications for the knowledge and skills required for success in specified technical areas. OP-TEC first developed The National Photonics Skill Standards for Technicians in 1995. Because photonics applications have undergone rapid change in the last several years, the standards have been revised twice; the third edition was completed in 2008. Revision efforts were based on advice and input from national representatives of the photonics industry. Skill standards are critical in maintaining the currency and relevance of OPTEC's model curricula and instructional materials. All OP-TEC materials referenced in this paper are based on these standards. Table 1 provides more detail on the structure, organization, and components of the standards. Copies can be downloaded from the OP-TEC website (www.op-tec.org).

\begin{tabular}{|c|c|}
\hline $\begin{array}{l}\text { Photonics Skill Standards } \\
\text { 1. Specifies the knowledge and skill requirements for a } \\
\text { variety of technicians in the photonics industry } \\
\text { 2. Provides the foundation for AAS curriculum and } \\
\text { materials development in photonics technology } \\
\text { 3. Can be adapted by local employers for curriculum } \\
\text { design at a particular college } \\
\text { 4. Provides benchmark (4+2) curriculum framework, } \\
\text { infusion curriculum, and advanced certificate } \\
\text { 5. Identifies six specialty areas for photonics technicians }\end{array}$ & $\begin{array}{l}\text { Organization of the Standards } \\
\text { Six specialty areas } \\
\text { Critical work functions for each specialty } \\
\text { Tasks } \\
\text { Skills } \\
\quad \text { - Employability and } \\
\text { - Technical }\end{array}$ \\
\hline $\begin{array}{l}\text { Critical Work Functions } \\
\text { General areas of responsibility or functions that are required } \\
\text { of a technician working in a specialty area } \\
\text { Example: Assemble various fiber-optic components and } \\
\text { modules into subsystems and understand their function }\end{array}$ & $\begin{array}{l}\text { Tasks } \\
\text { Observable and measurable activities that } \\
\text { technicians perform to accomplish a critical } \\
\text { work function } \\
\text { Example: Integrate fiber-optic components and } \\
\text { modules into specified systems }\end{array}$ \\
\hline \multicolumn{2}{|c|}{$\begin{array}{l}\text { Technical and Employability Skills } \\
\text { Basic abilities that are necessary for a technician to perform a task } \\
\text { Examples: } \\
\text { Technical: Test and verify initial source output and launch angles at source/fiber interface } \\
\text { Employability: Navigate the Internet to gather task-related information }\end{array}$} \\
\hline
\end{tabular}

National Photonics Skill Standards for Technicians

\subsection{Development of model AAS and infusion photonics curricula}

Skill standards are the foundation for developing curriculum. With these employer specifications, educators have the input they need to develop curricula that will effectively prepare students to enter the workforce. To further assist educators in developing these curricula, OP-TEC carefully examined the skill standards, talked with educators, and reviewed earlier curriculum designs to determine appropriate structures to meet current college fiscal constraints and photonics industry needs. As a result, OP-TEC published in 2010, two monographs ${ }^{4,5}$ that define the various types of photonics technicians employers require; present curriculum models for developing each type of technician; and offer educators a plan for designing and developing their curriculum.

OP-TEC identified three levels of technicians needed in today's high tech photonics workplace: (A) Photonics Technician Specialists; (B) Photonics Application and Systems Integration Technicians; and (C) Technicians in Other Fields. The levels differ in the knowledge and skills required, and thus differ in the course content of the programs that prepare technicians for the workplace. 
A. Photonics Technician Specialists - These technicians work as (a) R\&D laboratory technicians, (b) field service technicians for laser/optical equipment, and (c) development and test technicians for laser original equipment manufacturers (OEM). They require a high level of knowledge and skills in laser fundamentals and components, geometrical and wave optics and components, specific laser systems, electro-optics measurement equipment and techniques, and electro-optic instruments such as spectrophotometers and interferometers. A typical AAS curriculum for preparing Photonics Technician Specialists contains 5-8 photonics specialty courses and a strong electronics or electro-mechanical core. Developing an AAS Photonics program requires a college to invest in equipment and facilities. Typically it can take a college between six to eight years to fully implement this program. In section 3.2 of this report, OP-TEC provides a plan for starting with one or two photonics courses and expanding into a full AAS Photonics program at a rate that can be adjusted to meet a college's budgetary requirements.

B. Photonics Applications and Systems Integration Technicians - These type of technicians typically have educational backgrounds and experience in specialty fields in which photonics devices and applications are evident, such as manufacturing and materials processing, information technology, biomedical equipment, and defense and homeland security. A typical AAS curriculum for preparing Photonics Applications and Systems Integration Technicians contains two photonics courses infused into the existing curriculum for the specialty field. Because of severe cost restraints, most colleges need to begin a new photonics program by adding two or three photonics courses as a specialty onto a core curriculum, or by infusing two photonics courses in an existing specialty where photonics is an enabled technology.

C. Technicians in Other Fields-Technicians at this level work in fields such as consumer electronics, microelectromechanical systems (MEMS), semiconductors, and biotechnology. Specific equipment and/or applications of photonics in these and related fields have been identified; others are emerging. A typical AAS curriculum for preparing technicians at this level would include at least one course in photonics fundamentals.

These categories of technicians have become the standard used by ETA-International in developing a photonics technician national certification program. More information on this effort can be found at the websites for ETAInternational (www.eta-i.org ) or Workforce Florida (www.workforceflorida.com ).

Figure 1 shows the model curricula OP-TEC developed for each type of technician. A consistent feature of these models is that they involve a progression from general to more specific, depending on the photonics area that the student is preparing to enter. These curricula also support either an AAS Photonics program for preparing photonics technician specialists or infusion curricula for technical areas where photonics is an enabling technology. These infusion programs typically have one or two courses in photonics that provide students an opportunity to learn basic photonics concepts that allow them to better troubleshoot systemic problems related to their areas of responsibility. 


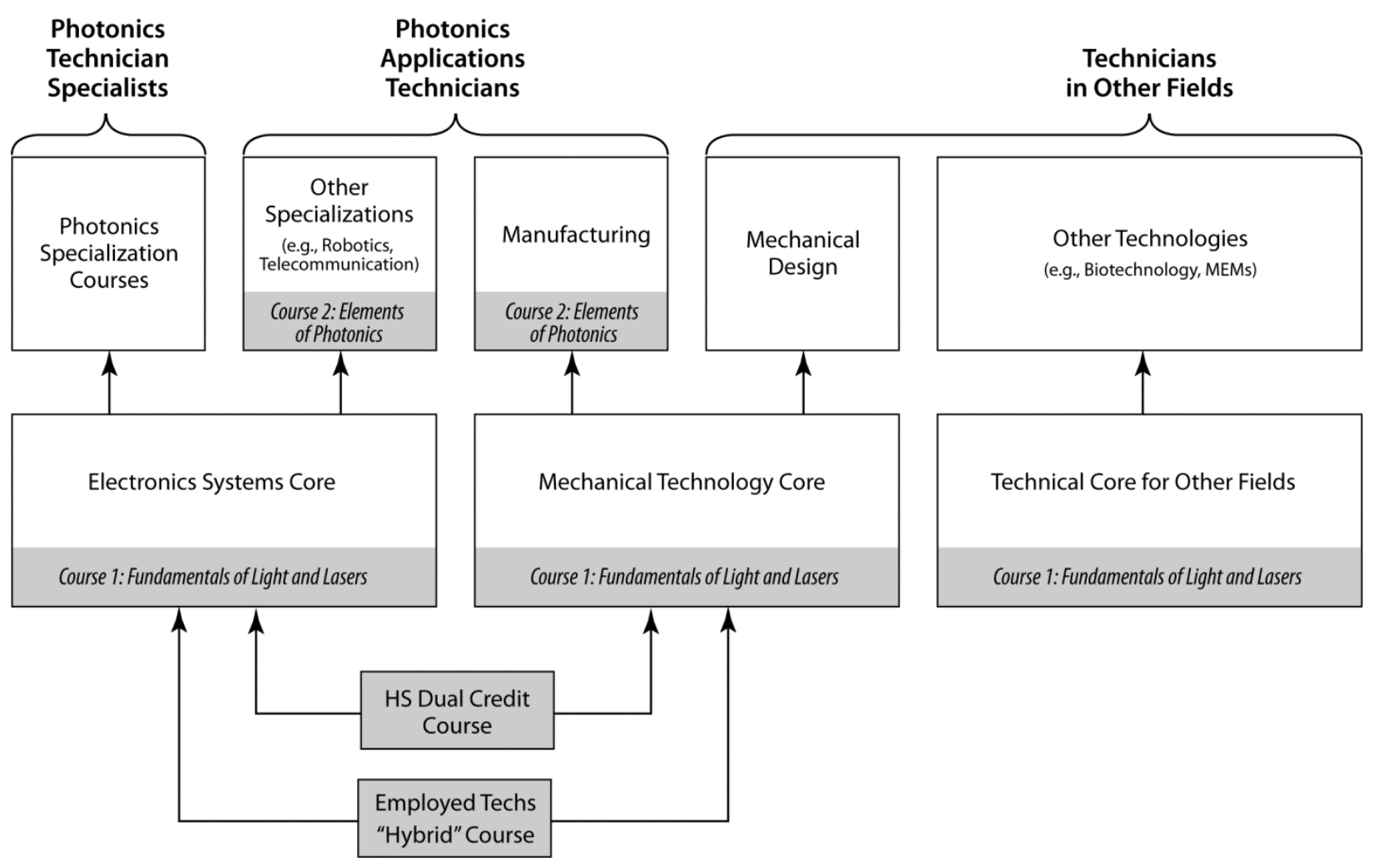

Figure 1. Recommended Curriculum Models for Three Levels of Photonics Technicians

In the monographs cited in references 4 and 5, OP-TEC provides educators details of the courses that should be considered for each technical core and specialty area depicted in Figure 1. OP-TEC also provides guidance in these monographs for building teams of employers and educators to select the appropriate curriculum for a college's service area, as well as for making decisions on the content of the courses within them.

\subsection{Development of instructional materials}

Most college faculty members have neither the time nor the incentive to design new curriculum models or to develop or revise instructional materials. OP-TEC staff members are equipped with the knowledge and experience to do this.

Therefore, OP-TEC undertook an extensive development effort to upgrade and expand its instructional materials base. The curriculum models and modular materials that have been created/revised provide the flexibility for faculty to tailor them to the specific needs of their local employers.

OP-TEC performed these upgrades and expansions using the curricula models shown in Figure 1 as guides for what courses needed to be developed and its skill standards as a base for selecting content for these courses. Two very distinct sets of material have emerged.

For Photonics Specialists: The photonics specialist requires an in-depth understanding of photonics. Students pursuing this level of understanding normally enroll in AAS Photonics programs where they receive rigorous instruction in photonics within the block of instruction labeled in Figure 1 as "photonics specialty courses". This instructional block usually consists of five to eight courses in photonics that start with basic photonics concepts, advance through geometric and wave optics, include the study of a variety of specific laser systems, and concludes with extensive work in designing, testing and calibrating lasers. OP-TEC's Laser Electro-Optics Technology (LEOT) series has for many years provided AAS Photonics programs instructional materials for pursuing advanced photonics studies. However to meet its 
skill standards, OP-TEC has recently developed the third edition of six of these LEOT courses. These new editions include the latest breakthroughs in photonics technology and ensure students have the knowledge and skills required of technicians in today's photonics industry. The full LEOT series is shown in Table 2 and can be viewed in more detail at www.op-tec.org. Four of the colleges currently teaching photonics have this level of specialization in lasers, optics and photonics.

\begin{tabular}{|l|}
\hline \multicolumn{1}{|c|}{ OP-TEC Laser Electro Optics Series } \\
\hline Introduction to Lasers (eleven modules)* \\
Geometrical Optics (nine modules)* \\
Laser Technology (fourteen modules)* \\
Light Sources and Wave Optics (nine modules)* \\
Laser/Electro-Optics Components (eleven modules)* \\
Laser/Electro-Optic Devices (eleven modules)* \\
Laser Electronics (nine modules) \\
Laser /Electro-Optics Measurements(eight modules) \\
$\qquad 3^{\text {rd }}$ Edition's available \\
\hline
\end{tabular}

Table 2. OP-TEC Laser Electro-Optics Series

For Photonics Systems Technicians: The other photonics specialists listed in Figure 1—Photonics Applications System Integration Technicians and Technicians in Other Fields - require less in-depth treatment of photonics during their course of study. Typically, while pursuing their course of study, these technicians are enrolled in technical programs in which photonics is an enabling technology; therefore they only require courses that present basic photonics concepts. To provide varying degrees of photonics basics, OP-TEC developed two courses.

The Fundamentals of Light and Lasers course provides all three categories of technicians a solid foundation in basic photonics concepts. OP-TEC developed and published the second edition of this course in 2012.

For technicians that require more knowledge of photonics-Photonics Applications and Systems Integration Technicians - OP-TEC developed the Elements of Photonics Course that builds-off of the Fundamentals of Light and Lasers course and provides students an understanding of different types of lasers, their basic operational capabilities and applications, and methods for determining their output characteristics. The topics covered in these two courses are listed in Table 3. This is the level of photonics specialization that is provided in most of the colleges that offer photonics technician education.

\begin{tabular}{|c|c|}
\hline $\begin{array}{c}\text { Fundamentals of Light and } \\
\text { Lasers }\end{array}$ & Elements of Photonics \\
\hline $\begin{array}{c}\text { Nature and Properties of Light } \\
\text { Optical Handling and }\end{array}$ & Operational Characteristics of \\
Positioning & Lasers \\
Laser Safety & Specific Laser Types \\
Basic Geometric Optics & Optical Detectors and Human \\
Basic Physical Optics & Vision \\
Principles of Lasers & Specialization Module 1 \\
& Specialization Module 2 \\
& Specialization Module 3 \\
\hline
\end{tabular}

Table 3 Modules in the Fundamanetals of Light and Lasers and Elements of Photonics Courses

The specialization modules in Table 4 provide a means to customize the Elements of Photonics course so students can learn how photonics enables various systems and processes in the technical areas they are earning their AAS degrees. 
These specialization modules are also often used independently of the Elements of Photonics Course to meet specific learning objectives related to their content.

\begin{tabular}{|c|c|c|}
\hline $\begin{array}{l}\text { Manufacturing } \\
\text { Laser Welding and Surface } \\
\text { Treatment } \\
\text { Laser Material Removal: Drilling, } \\
\text { Cutting, and Marking } \\
\text { Lasers in Testing and Measurements: } \\
\text { Alignment Profiling and Position } \\
\text { Sensing } \\
\text { Lasers in Testing: Interferometric } \\
\text { Methods and Nondestructive Testing } \\
\text { Laser Concepts } \\
\text { Fiber Laser Basics } \\
\text { Fiber Laser Applications }\end{array}$ & $\begin{array}{l}\text { Biomedicine } \\
\text { Lasers in Medicine and Surgery } \\
\text { Therapeutic Applications of } \\
\text { Lasers } \\
\text { Diagnostic Applications of } \\
\text { Lasers } \\
\text { Environmental Monitoring } \\
\text { Basics of Spectroscopy } \\
\text { Spectroscopy and Remote } \\
\text { Sensing } \\
\text { Spectroscopy and Pollution } \\
\text { Monitoring }\end{array}$ & $\begin{array}{l}\text { Forensic Science and Homeland } \\
\text { Security } \\
\text { Lasers in Forensic Science and } \\
\text { Homeland Security } \\
\text { Infrared Systems for Homeland } \\
\text { Security } \\
\text { Imagining System Performance for } \\
\text { Homeland Security } \\
\text { Optoelectronics } \\
\text { Photonics in Nanotechnology } \\
\text { Photonics Principles in Photovoltaic } \\
\text { Cell Technology } \\
\text { Photonics in Nanotechnology } \\
\text { Measurements: A Study of Atomic } \\
\text { Force Microscopy }\end{array}$ \\
\hline
\end{tabular}

Table 4. Specialty Modules for Elements of Photonics and Independent Study

More details on the two basic concept courses and the specialization modules are available at www.op-tec.org .

\subsection{E-book development and enhancements}

OP-TEC has begun developing E-book versions of its teaching materials. The original motivation for this development was to reduce the costs for students to acquire our textbooks. However, as the development and testing progressed it became clear that the e-book format had the capability of introducing multi-media sources that could enhance student learning.

OP-TEC produced and published in 2010, an e-book version of the Fundamentals of Light and Lasers course. This book incorporated the usual E-book features, of a searchable table of contents, read-to-me capability, and highlighting.

Additionally, it included applets describing optical phenomena. OP-TEC also developed electronic learning enhancements and video tutorials in math/problem-solving, difficult photonics concepts and laboratory procedures. The resulting e-book is now being offered through Follett-operated campus book stores. It is the only E-book currently on the market that is specifically designed to present basic photonics concepts to students in technician programs. The price of the E-book is at least $25 \%$ less than its print version.

A pilot test of the E-book with students in five colleges indicated that they regularly accessed the videos embedded within the book. OP-TEC also discovered that instructors were using the math and concept videos as classroom teaching tools. Recognizing their educational value, OP-TEC has made them available at no cost to faculty and students in public institutions. They can be accessed at http://optecvideo.opteccrm.org.

\subsection{Establishment of the OP-TEC Photonics College Network}

In 2009, OP-TEC established the OP-TEC Photonics College Network (OPCN). The purposes of this organization are:

1. Expand the photonics capacity of U.S. colleges by strengthening/enhancing their existing and new technician education offerings and by enlarging student enrollment.

2. Network with colleagues and provide professional development.

3. Share ideas and best practices in curriculum, teaching, labs, student recruitment, student retention and relations with employers.

4. Provide advice and guidance to OP-TEC regarding its initiatives, strategies and services. 
The membership for OPCN is open to all colleges in the U.S. that teach photonics within any of their technical programs. OPCN membership is also open to colleges that are taking significant steps in planning new photonics offerings on their campuses. Giving OPCN access to the colleges with developing programs assists them in accelerating their implementation efforts. The OPCN currently has twenty-eight college members and thirty-one individual members. OPCN is the only formally established network in the country for colleges currently offering, or in the process of offering photonics programs.

Through quarterly OP-TEC sponsored teleconference meetings and annual face-to-face meetings at the HI-TEC conference members stay connected with each other and have an opportunity to hear updates on the latest teaching practices, laboratory developments, safety issues, and technology breakthroughs in photonics. OP-TEC provides fellowships and travel for OPCN members to attend the HI-TEC Annual Conference.

OP-TEC is currently assisting over eighty colleges throughout the U.S. that are in various planning stages to develop photonics programs. We estimate that more than half of these colleges will eventually join OPCN, thus more than doubling the membership of this network over the next 4 years.

\subsection{Expanding photonics enrollment at two-year colleges through innovative recruiting strategies}

Student enrollment in most existing photonics programs is disappointingly low. These low enrollments not only forecast low numbers of graduating technicians, they also place the photonics programs at risk of being closed. The most effective strategy to increase student enrollment is to build the "high school pipeline" to assure that more recent high school graduates will articulate into photonics AAS degree programs. Effective student recruitment programs are essential to ensuring these articulation numbers are high.

Student recruiting is a multi-faceted challenge to fill college classrooms with qualified and interested students. Encouraging and preparing high school students to enroll in college photonics programs must be a proactive pursuit. It requires colleges to interact with students to show them that photonics is something they would find interesting and is a good career choice. One strategy that OP-TEC supports is for colleges to visit local high schools and present photonics demonstrations, or have employers make visits and speak about career opportunities in photonics. Another effective recruitment strategy is to invite prospective students, their parents and their counselors to college campuses to see the college's photonics facilities and to talk with enrolled students about their experiences. Educational and technical conferences are also excellent student recruitment tools. They provide forums for colleges to present photonics and its career opportunities to high school faculty and administrators who are typically looking for challenging and financially rewarding post-graduation opportunities for their students. OP-TEC staff and its Partner Colleges participate in over 250 of these outreach activities each year.

Along with the outreach activities, mentioned above, OP-TEC has also worked with its Partner Colleges to develop several weeklong summer institutes. These institutes typically include high school students, teachers, and counselors. The participants perform photonics laboratories, observe photonics demonstrations, hear from photonics employers, and enjoy other campus activities. Students leave these institutes with an awareness of photonics and an excitement about technology and careers related to it. Counselors and teachers leave with an understanding of photonics and a better sense of how to introduce it at their schools. OP-TEC has developed two monographs $\mathrm{s}^{6,7}$ on different types of successful summer institutes that document their designs and provide guidelines for other colleges to plan similar programs.

Another recruiting strategy is the hiring and training of a dedicated photonics recruiter. Most colleges have one recruiter for all their technical programs. Typically these recruiters are college staff members who have an elementary understanding of the technical programs they represent. With so many programs to represent, it is difficult for general recruiters to acquire expertise in each technology field and to build a relationship with the students they meet. The dedicated recruiter is a person who has responsibility for only the photonics program. Under the OP-TEC model, this person is hired by a college's photonics department with the sole responsibility to recruit for it. To ensure this person is credible and knowledgeable about the college's photonics program, the recruiter is required to attend a short training program given by the photonics faculty. After the first few school visits, these recruiters debrief faculty on additional knowledge they need. The OP-TEC model also suggests that the compensation of the recruiter be linked to their 
recruitment success. With a sole purpose of recruiting for the photonics program, armed with a knowledge of this program, and incentivized financially, the dedicate recruiter has proven very effective in keeping enrollments high within OP-TEC's Partner Colleges photonics programs. OP-TEC has encouraged its other OPCN members to adopt this model and has produced a monograph ${ }^{8}$ to export it to other colleges.

A more systemic approach to building the "high school pipeline" is to encourage and assist high schools to create Career Pathways, which provide an alternative high school curriculum for applied learners who are interested in technician careers. This strategy encourages high schools to develop articulated programs with their local two-year colleges that include several technology-based courses to prepare students for college technical programs and allow them to earn college credit while still in high school. These courses are natural recruitment agents. They allow students to become immersed in technology, gain confidence in learning it, discover their level of interest in it, and explore career opportunities offered by it. All curricula developed by OP-TEC are based on career pathways and use a structure that includes dual-credit opportunities. More detail about photonics technician career pathways can be found in the Career Pathways for STEM Technicians ${ }^{9}$ book recently published by Dan Hull. See www.op-tec.org/CPST.

\subsection{Increasing the number of two-year colleges offering photonics}

OP-TEC is working diligently to identify two-year colleges within the U.S. that are offering photonics and nurturing colleges that are in the process of planning new photonics courses and programs. OP-TEC also actively recruits college faculty to consider teaching new photonics courses or programs.

The OP-TEC college recruitment process consists of five phases. In the awareness phase, OP-TEC, through its website, blogs, conference presentations, workshops and webinars provides information to colleges about career opportunities for photonics technicians and the successes other colleges have had in conducting and building photonics programs. In the commitment phase, OP-TEC contacts colleges that have expressed an interest in learning more about photonics and the process of developing educational programs in it. If a college makes the decision to commit resources to further explore and plan the implementation of photonics, OP-TEC moves it into the assessment phase. Once a college enters the assessment phase, it becomes eligible for OPCN membership and the special mentoring needed to carry it through this phase, as well as the preparation and implementation phases that follow. While in these final three phases, OP-TEC provides the following services:

1. Program assessment to select a photonics specialty area

2. Technical assistance in curriculum design and selecting instructional materials

3. Technical assistance in laboratory design and laser safety

4. Consulting in selecting laboratory equipment

5. Training to prepare faculty

OP-TEC has successfully executed this recruitment process for the entire six years of its operation; we have already assisted nine colleges in implementing photonics offerings on their campuses. Currently there are eighty-four colleges in OP-TEC's recruiting process, with twenty-nine in the assessment and preparation phase. When there is a turnaround of the economy and state governments becoming more financially stable, we predict that nearly all these twenty-nine colleges will start photonics courses/programs over the next few years. Such an infusion of photonics colleges will provide students around the U.S. more access to photonics studies and provide the basis for increasing the number of qualified photonics technicians entering the workforce.

\section{OP-TEC'S VALUE ADDED FACTORS}

The measure of OP-TEC's effectiveness is how it impacts its customers and what value it adds to their operations. OPTEC has three customers: U.S. two-year colleges, photonics employers and students who could benefit from a career as a photonics technician. Section two of this paper focused heavily on accomplishments that were academically oriented. This section will focus on OP-TEC's impact on photonics employers. 
OP-TEC's mission cuts to the heart of what employers need to run effective organizations - a highly qualified workforce. To accomplish this mission, OP-TEC has employed a three prong approach to closing the supply/demand gap for photonics technicians.

\subsection{Resurrecting dead or dying AAS degree programs for educating photonics technicians}

Several two-year colleges within the U.S. with existing AAS Photonics programs are facing closure. The reasons for these closures are often retirement of key faculty, outdated curriculum and equipment, loss of contact with employers, and weak or crumbling student pipelines. We believe it is much easier to save a photonics program than build a new one. As such, OP-TEC has invested in considerable efforts to resurrect five established programs in different areas of the country. These resurrection efforts include issuing mini-grants to hire dedicated recruiters or establish summer institutes, revising existing curriculum to reduce photonics courses, while keeping it "skill standards compliant", developing and assisting in the implementation of dual credit courses to recharge the student pipeline, assisting in preparing proposals for the funding of new equipment, and offering faculty development courses to help build faculty succession options at colleges. The five rescued programs are all still active today and are generating graduates for the photonics workforce. To alert other colleges to its work in this area, OP-TEC has developed a monograph ${ }^{10}$ that details its efforts in assisting one of these five colleges in rebuilding its program.

\subsection{Infusing photonics in technical programs enabled by photonics}

The second prong of the approach focuses on encouraging and assisting colleges with new photonics programs. The major implementation challenge these new colleges face is finding funds, especially in today's economy, for equipping photonics laboratories. OP-TEC recommends and supports a low cost approach for starting photonics programs that meets the demands of employers and allows colleges to keep equipment and faculty costs as low as possible.

OP-TEC's skill standards work and other collaborative efforts with photonics employers identified that much of the demand for photonics technicians resides in companies that use photonics as an enabling technology. These companies do not require the photonics specialist technician defined in the last section of the paper, but instead require a photonics systems technician. This finding meant that colleges could begin offering photonics on their campuses by infusing into existing technical programs, enabled by photonics, one or two photonics courses.

As shown in section 2.2 of this paper and explained in section 2.3, two courses that serve this purpose are OP-TEC's Fundamentals of Light and Lasers and Elements of Photonics courses. Both courses have extensive laboratory components, but the required equipment to present basic photonics concepts is quite inexpensive and well within the means of most two-year colleges - even in challenging economic times. This means that the eighty plus colleges currently in the OP-TEC's college recruiting process will only face modest costs for implementing photonics courses because of equipment and faculty expenses. It should also be mentioned that colleges who start with just two courses need not stay at this level when enrollment increases, or more equipment money becomes available. OP-TEC has developed a photonics program expansion plan based on staggered certificates that allows colleges to add courses to their programs at a rate that fits their budgets. Thus, colleges can grow their photonics programs in a step-by-step manner that fits their budgets and employer demands.

\subsection{Educating employed technicians}

Because of the long term shortage of new photonics technicians, photonics employers have had to staff their positions with technicians that do not have education and training in this field. This means that many technicians currently working in industry do not have the optics and photonics knowledge and skills they need. These currently employed technicians could handle greater responsibility and possibly reduce the need to hire more technicians, if they had a basic understanding of photonics. If existing technicians can handle greater responsibility, then less will be needed and the demand for technicians will decrease. This decrease in demand works to reduce the supply/demand gap and provides photonics employers a more robust photonics technician workforce.

OP-TEC has developed a course for providing employed technicians the basic concepts of photonics. This course is based on the Fundamentals of Light and Lasers course presented in section 2.3 and is offered in an online format. This format was chosen to provide both employers and technicians scheduling flexibility in avoiding work or personal 
conflicts. This course will be offered thorough selected OPCN colleges starting in fall 2012. These colleges will offer the course, establish schedules with employers for completing it, monitor the progress of the enrolled technicians, and issue college credit. OP-TEC will provide the course platform and online instruction. Once the online instruction is completed, the OPCN colleges will work with their employers to set-up a capstone laboratory session at either the college or employer's site. These capstones will allow students to complete the laboratory component of the Fundamentals of Light and Lasers course. Employers and colleges can also schedule laboratory sessions at various break points in the course like at the end of each of the six modules. Employers interested in enrolling their technicians in this course should contact the authors (souders@op-tec.org, dan37hull@gmail.com )

\subsection{Regionalizing OP-TEC's support to employers}

OP-TEC is pursuing a regionalization strategy that will provide employers tighter alliances with their local two-year colleges allowing them to exercise more influence in preparing students for their workplaces. Networking between twoyear colleges and photonics employers is vital to building effective photonics educational programs. To encourage this networking, beginning in 2010, OP-TEC began creating a regional approach to working with colleges and photonics employers. This approach started with first analyzing the distribution of photonics employers in the U.S. and determining the most effective way to divide the country into regions. As a result, seven regions were defined and are shown in Figure 2 along with the number of employer in each region.

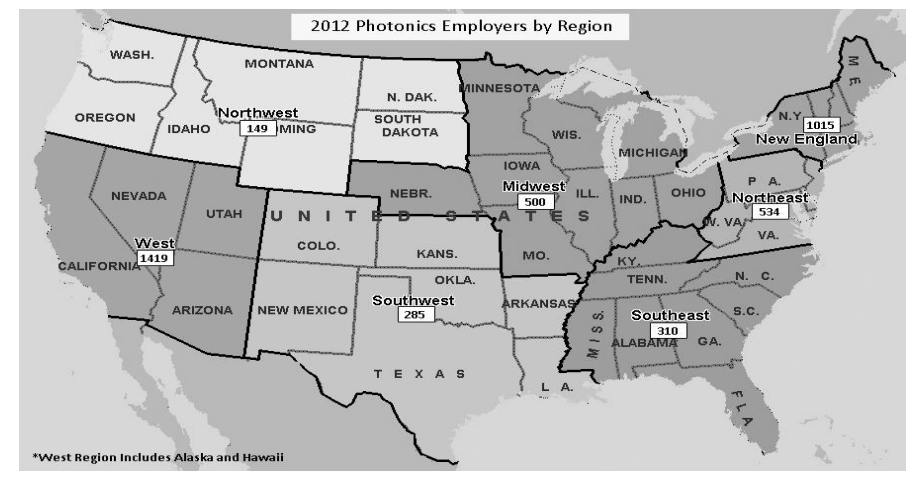

Figure 2. U.S. photonics regions defined by OP-TEC

OP-TEC then assigned its Partner Colleges in the Northeast, Southeast, Midwest, and West regions the leadership responsibility for establishing photonics advisory councils in these regions composed of photonics employers and twoyear college educators. OP-TEC staff retained the leadership responsibility for the Southwest and Northwest regions and merged the New England and Northeast regions under Camden County College's and IUP's leadership. Organizational meetings among photonics employers and educators were held in the six active regions and photonics advisory councils were formed.

The regional councils have met several times via quarterly teleconferences and annual face-to-face meetings. At these meetings, employers and educators have reviewed OP-TEC's photonics technician skill standards and begun the process of regionalizing them to better define specific local needs; worked with OP-TEC to develop an employer needs assessment for their regions; discussed better processes for establishing internships and selecting students for them; determined requirements for professionals at photonics companies to become adjuncts at local two-year colleges; organized joint activities for raising the awareness of photonics careers and employment opportunities within a region; and set plans for expanding the membership of these councils.

Feedback from employers and educators attending these meetings was very positive. Educators felt that regional councils would provide them the following benefits:

1. A larger base of employers to support college photonics initiatives

2. More opportunity to provide customized training and certification programs

3. More qualified adjuncts

4. Greater opportunities for student internships 
5. Opportunities to collaborate with other colleges within the region to share resources and develop a broader range of technical programs

6. Greater access to employers through regional employer councils versus individual interactions.

Likewise, employers listed the following as benefits to them:

1. Networking with other employers to solve common problems

2. The potential to expand their impact on setting the curriculum for their future employees

3. Opportunities for interacting with regional colleges to develop customized training programs

4. Greater insight and choice in hiring photonics technicians

5. Teaching opportunities for employees

\section{OP-TEC's continuing and future efforts}

OP-TEC's current and future agenda is largely dictated by the following challenges:

1. A need to increase the capacity of the U.S.'s two-year college system to prepare photonics technicians for the workforce.

2. A need to recruit more students into two-year college photonics programs and develop better educational practices for retaining these students.

3. A need to provide employed technicians educational opportunities to stay current with the latest developments in photonics.

4. Provide the U.S.'s precision optics industry the technician workforce needed to maintain the U.S.'s capability in this important defense-related industry.

OP-TEC is in position to meet all these challenges now and in the future.

1. Currently eighty-four colleges are in OP-TEC's recruitment process and thirty-four of them are within a year or two of offering photonics courses on their campuses.

2. The OPCN is growing and OP-TEC is using its resources to strengthen and increase the enrollments in the photonics offerings of all the twenty-eight member colleges.

3. OP-TEC's online faculty development courses have already prepared over sixty instructors to teach photonics and with its new Open Entry/Open Exit format will attract even greater numbers of faculty from around the country.

4. OP-TEC will continue to regionalize its efforts in building photonics enrollments at two-year colleges.

a. Work is underway by regional councils to assist two-year colleges in their regions to increase the quality, size, and depth of their photonics programs.

b. Regional councils are working to adapt OP-TEC skill standards, curricula, and instructional materials.

c. OP-TEC and the regional councils are developing processes and procedures so OP-TEC Partner Colleges can work as flagship schools within their regions and assist other colleges to more quickly implement photonics programs.

d. OP-TEC partner colleges are developing expertise in specific photonics technology areas to better serve students and employers in their regions and also to become national resources for preparing technicians to work in these areas.

5. In fall 2012, OP-TEC will offer through its OPCN a major program that will give employed photonics technicians an opportunity to learn basic photonics concepts and open the doors for more customized educational opportunities in the future.

6. OP-TEC has identified several emerging technologies that photonics technicians will need to learn and apply and is in the process of planning instructional materials to meet that need.

7. In fall 2012, OP-TEC will add to its responsibilities efforts to develop a fully redesigned AAS Precision Optics program. 
a. In 2009, OP-TEC developed the National Precision Optics Skill Standards for Technicians.

b. In 2010, OP-TEC developed an AAS Precision Optics Curriculum based on the skill standards.

c. In fall 2012, OP-TEC will initiate an effort to develop instructional materials to support the precision optics curriculum and pilot test it. This work is projected to be completed in 2016.

\section{FINAL THOUGHTS}

As this paper has presented and the list in the preceding section implies, OP-TEC is making significant strides toward providing U.S. photonics employers the technicians their companies require.

To fully succeed in this quest, OP-TEC needs employers to support its efforts. Photonics educational programs around the country cannot reach their fullest potential in serving employers without input from them. Serving on regional advisory councils is one way employers can make this input and have an influence on the preparation of their future employees. For OP-TEC to best serve employers, it must stay abreast of the latest technical developments in photonics and have a sense of where the industry is headed. Professional societies are key to obtaining this information and it is important OP-TEC work closely with them. Any assistance employers can provide to network OP-TEC with the professional societies or to encourage these societies to work collaboratively with OP-TEC will generate results that will benefit both the professional society and OP-TEC and ultimately the photonics industry.

Two-year college support is also important in OP-TEC meeting its mission. As OP-TEC's mission clearly states, twoyear colleges are the primary means for developing the technician workforce photonics employers need. OP-TEC is constantly recruiting two-year colleges that have an interest in implementing new photonics programs, resurrecting old ones, or enhancing current programs. OP-TEC needs two-year colleges to attend its workshops and learn about the opportunities that exist for their students in photonics and the support OP-TEC can provide to help colleges assess, plan, and implement photonics programs. Two-year colleges need to provide faculty opportunity to participate in OP-TEC's online faculty development courses and assist these faculty in integrating these courses into existing curriculum. Once decisions are made to implement a photonics course or program, colleges need to encourage their faculty to join OPCN and network with other photonics educators to build photonics offerings that will meet their employer and student needs.

[1] Hull, D.M., and Gutzwiller, R., "Two-year college enrollment and completion rates: An estimation of workforce supply for technicians in optics, photonics, and laser technology," OP-TEC Monograph, (2008).

[2] Hull, D.M., Ruggiere, P., and Illich, P., "Photonics Technician Employment in the United States: An Industry Survey of Current and Future Demand in 2009 for Education and Training," OP-TEC Monograph, (2009).

[3] Souders, J., and Hull, D., "National Photonics Skill Standards for Technicians," OP-TEC Monograph,(2008).

[4] Hull, D., and Souders, J., "Providing Photonics Education for Technicians," OP-TEC Monograph, (2010).

[5] Souders, J., and Hull, D., “A General Curriculum Framework for Infusing Enabling Technologies into Two-Year Postsecondary Technical Programs," OP-TEC Monograph, (2010).

[6]Zhou, F., "Outreach Activities to Enlist High School Students for Electro-Optics Technician Programs at Indiana University of Pennsylvania, Northpointe Two Year Campus," OP-TEC Monograph, (2009).

[7]Pedrotti, J., and Hull, D., “TSTC Waco's Photonics Summer Institutes for High School Science and Technology Teachers," OPTEC Monograph, (2009).

[8]Panayiotou, C., "Transforming Electronic Engineering Technology by Infusing Photonics," OP-TEC Monograph, (2008).

[9] Hull, D., "Career Pathways for STEM Technicians," University of Central Florida, (2012).

[10]Grant, E., and Hull D., "Restoring a Declining Photonics Program at Tri-County College”, OP-TEC Monograph, (2010). 